\title{
Disputa, imposição e negação em trabalhos escolares sobre história e cultura afro-brasileira e africana
}

Dispute, imposition and refusal in school works on afro-brazilian and african history and culture

\section{Sandra Aparecida Batista}

\author{
Universidade Estadual de Ponta Grossa - UEPG - Ponta Grossa - Paraná - Brasil
}

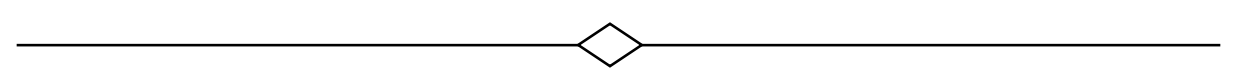

Resumo: Diante dos processos de disputa, imposição e negação a respeito da história e cultura Afro-Brasileira e Africana, o propósito da pesquisa é identificar e analisar as respectivas representações em trabalhos escolares do Colégio Estadual do Campo Dr. Antonio Pereira lima, Distrito Panema, município de Santa Mariana, Paraná. As fontes foram produzidas para o Dia Nacional da Consciência Negra no período de 2013 a 2015, sendo divididas em dois grupos compostos por textos e imagens: o primeiro parte da hipótese da existência de um discurso estereotipado e preconceituoso advindo da classe dominante branca a respeito da história e cultura Afro-Brasileira e Africana; já o segundo surge possivelmente da imposição de um novo discurso, fruto das reivindicações de reconhecimento e valorização da diversidade cultural advogadas pelo Movimento Negro e por meio da Lei 10 639/03. Este estudo possibilita estabelecer paralelos entre representações advindas do "sistema hegemônico branco e ocidentalizado" e as representações anti-hegemônicas, considerando que o texto da Lei 10 639/03, que insere o ensino de história e cultura Afro-Brasileira e Africana nas escolas, também se constitui em uma representação, e não anula os processos de negociação, conflitos e tensões entre o padrão cultural negro e africano e o padrão branco europeu na dinâmica pedagógica escolar. A partir do debate em torno do conceito de representações de Chartier (1990; 1991; 2002), as representações são tomadas como estratégias e práticas de tensionamento em meio às relações de poder. Portanto, não se tratam de uma questão de verdade e falsidade, mas de uma lógica de representação que manipula e legitima o discurso de quem enuncia.

Palavras-chave: Representações, história e cultura Afro-Brasileira e Africana. Trabalhos escolares.

Abstract: In the face of the processes of dispute, imposition and denial regarding AfroBrazilian and African history and culture, the purpose of the research is to identify and analyze the respective representations in school works of the State School of the Field Dr. Antonio Pereira Lima, Panema District, municipality Of Santa Mariana, Paraná. The sources were produced for the National Black Consciousness Day from 2013 to 2015, being divided into two groups composed of texts and images: the first, part of the hypothesis of the existence of a stereotyped and biased discourse coming from the white ruling class about Of Afro-Brazilian and African history and culture; The second is possibly the imposition of a new discourse, as a result of the claims of recognition and appreciation of cultural diversity advocated by the Black Movement and by Law 10 $639 / 03$. This study makes it possible to establish parallels between representations derived from the "white and Westernized hegemonic system" and anti-hegemonic representations, considering that the text of Law 10 639/03, which inserts the teaching of Afro-Brazilian and African history and culture in schools, It also constitutes a representation and does not negate the negotiation processes, conflicts and tensions between the black and African cultural pattern and the European white standard in the school pedagogical dynamics. From the debate around Chartier concept of representations $(1990 ; 1991 ; 2002)$, representations are taken as strategies and practices of tensioning amid power relations. Therefore, they are not a matter of truth and falsity, but of a logic of representation that manipulates and legitimizes the speech of the enunciator.

Keywords: Afro-Brazilian and African representations, history and culture. School work. 


\section{Introdução}

Os Movimentos Sociais, mais especificamente - Movimento Negro, diante dos históricos conflitos e tensões entre o padrão cultural negro e africano e o padrão branco europeu, tem reivindicado cada vez mais o reconhecimento e a valorização de sua cultura. Essa demanda associada às políticas afirmativas e de reorganização do capital impulsionaram a promulgação da Lei 10.639/03 incluindo a obrigatoriedade da temática "História e Cultura Afro-Brasileira" nos currículos escolares.

Contudo, a maneira como cada grupo é representado social e culturalmente e como representa a si próprio, nos faz refletir sobre as estratégias simbólicas envolvidas. Diante do exposto, o propósito da investigação é identificar e analisar como a história e cultura Afro-Brasileira e Africana são representadas em trabalhos escolares produzidos em face do Dia Nacional da Consciência Negra, considerando a importância desta data, as contribuições da referida lei e a questão das representações. Para tanto, o objeto deste estudo são as representações presentes nos mencionados trabalhos feitos pelos estudantes, encarados aqui como expressões de processos de disputa, imposição e negação da história e cultura Afro-Brasileira e Africana.

As fontes referem-se aos trabalhos escolares produzidos no Colégio Estadual do Campo Dr. Antonio Pereira Lima, localizado no Distrito Panema, município de Santa Mariana, Paraná, no período de 2013 a 2015. Com a determinação da Lei 10 639/03, que altera a LDB 9394/96, incluindo a obrigatoriedade do Ensino de História e Cultura Afro-Brasileira e Africana nos currículos escolares, e com a existência da Equipe Multidisciplinar ${ }^{1}$ na instituição, há pelo

\footnotetext{
1 As Equipes Multidisciplinares são instâncias de organização do trabalho escolar, coordenadas pela equipe pedagógica, e instituídas por Instrução da SUED/SEED, de acordo com o disposto no art. 8o da Deliberação no 04/06 - CEE/PR, com a finalidade de orientar e auxiliar o desenvolvimento das ações relativas à Educação das relações Étnico-Raciais e ao Ensino de História e Cultura Afro-Brasileira e Africana ao longo do período letivo para que o aluno negro valorize a história de seu povo, sua cultura, e da contribuição dada para o país e para a humanidade.
}

menos cinco anos são desenvolvidos no Colégio trabalhos atendendo a determinação da referida Lei e para implantação do Plano de Ação da Equipe Multidisciplinar.

Os trabalhos escolares selecionados foram produzidos por alunos do Ensino Fundamental e Médio principalmente nas áreas de Ciências Humanas (História, Geografia e Sociologia) e de Linguagens (Língua Portuguesa e Artes), realizados principalmente no mês de novembro em razão do Seminário de Encerramento da Equipe Multidisciplinar e do Dia Nacional da Consciência Negra² ${ }^{2}$ São trabalhos compostos basicamente de imagens e textos, pois tendo em vista que as exposições formam um todo, bem como os cartazes expressam a aliança entre imagem e texto, as duas modalidades passam a compor um conjunto razoavelmente complementar para ambas. A pesquisa está organizada em dois conjuntos de trabalhos escolares, os quais são detalhados no terceiro subtítulo do presente artigo, com o intuito de analisar os elementos integrantes dos processos ligados às representações que retratam a história e cultura Afro-Brasileira e Africana.

O primeiro conjunto de imagens e textos parte da hipótese da existência de um discurso estereotipado e preconceituoso advindo da classe dominante branca e historicamente disseminado. As referidas representações foram intituladas na pesquisa nos seguintes trabalhos escolares: "escravizado submisso e passivo" (imagem 1); "miscigenação de raças $^{3}$ e o mito da democracia

\footnotetext{
2 O Dia Nacional da Consciência Negra é celebrado em 20 de novembro, dia da morte de Zumbi dos Palmares, líder do conhecido e reconhecido Quilombo dos Palmares, comunidade livre formada por escravos fugitivos dos engenhos, índios e brancos pobres expulsos das fazendas. Zumbi é considerado um dos grandes líderes de nossa história, lutou pela liberdade de culto, religião e prática da cultura africana no Brasil Colonial. O Movimento Negro reivindica essa data e figura histórica como símbolo de resistência negra à escravidão na época do Brasil Colonial.

3 "No século XVIII, a cor da pele foi considerada como um critério fundamental e divisor d'água entre as chamadas raças. Por isso, que a espécie humana ficou dividida em três raças estancas que resistem até hoje no imaginário coletivo e na terminologia científica: raça branca, negra e amarela" (MUNANGA, 2013, p. 3). Contudo, Munanga (2013) esclarece que, tendo em vista os entendimentos atuais de áreas como a própria genética humana, biologia molecular e bioquímica, raça é um "[...] conceito cientificamente inoperante para explicar a diversidade humana e para dividi-la em raças estancas. Ou
} 
racial" (imagem 2); "África negra, exótica e pobre", retratada pela fome, miséria, doenças, savanas, animais, e habitada somente por negros (imagem 3); e "abolição da escravatura" (imagem 4).

Já o segundo grupo surge possivelmente da imposição de um novo discurso fruto das reivindicações do Movimento Negro e da Lei 10 639/03 que tende a impor a sua concepção de mundo como legítima e verdadeira, numa lógica de relações de poder. Esse grupo é composto pelas seguintes imagens assim intituladas na pesquisa: "Zumbi dos Palmares e o Dia Nacional da Consciência Negra" (imagem 1); "resistências escravas" (imagem 2) "(in) visibilidade do continente africano" (imagem 3); "pirâmides do Egito e África como continente e não país (imagem 4); "África como berço da humanidade e do conhecimento" (imagem 5).

Desse modo, no primeiro grupo são analisados textos e imagens que apresentam representações advindas do "sistema hegemônico branco e ocidentalizado", de cunho preconceituoso, discriminatório e estereotipado da história e cultura Afro-Brasileira e Africana. Na mesma perspectiva do olhar do Movimento Negro e das reivindicações que culminaram entre outros direitos na Lei 10 639/03, estes trabalhos mostram a existência de um "[...] imaginário étnico-racial que privilegia a brancura e valoriza principalmente as raízes européias da sua cultura, ignorando ou pouco valorizando as outras culturas, que são a indígena, a africana e asiática" (BRASIL, 2004, p. 8).

Posteriormente, no segundo conjunto de imagens e textos são analisados trabalhos que apresentam representações que versam sobre 0 reconhecimento e valorização da história e cultura afro-brasileira e africana. Nesse caso, atendem a determinação da Lei 10.639/03 que estabelece em seu artigo 26-A, inciso 10: "[...] o estudo da História da África e dos Africanos, a luta dos negros no Brasil, a cultura negra brasileira e o negro na formação da sociedade nacional, resgatando a contribuição do

seja, biológica e cientificamente, as raças não existem" (MUNANGA, 2013, p. 3). povo negro nas áreas social, econômica e política pertinentes à História do Brasil” (BRASIL, 2003).

Tendo em vista o segundo grupo, consideramos que inclusive a Lei 10 639/03 e seu respectivo texto, constituem também uma representação, pois impõe um novo discurso como uma enunciação verdadeira, ou seja, incorre no que Chartier (1991) chama de lógica hegemônica de produção de verdades. Contudo, o presente trabalho não tem por objetivo estabelecer a promulgação da Lei 10 639/03 como um marco, até mesmo porque os trabalhos selecionados para esta pesquisa mostram que no ambiente escolar houve tanto avanços no que diz respeito à implantação das determinações da referida lei, como ainda existem desafios a serem enfrentados.

Portanto, a análise dos trabalhos escolares possibilita identificar e estabelecer paralelos entre representações que descrevem a discriminação, estigmas e estereótipos ${ }^{4}$ da história e cultura AfroBrasileira e Africana, e aquelas que ressaltam o reconhecimento e a valorização da diversidade cultural. Considera-se igualmente que os trabalhos escolares não são isentos de processos de negociação, conflitos e tensões entre o padrão cultural negro e africano e o padrão branco europeu.

Assim, o referencial teórico debatido com maior ênfase no segundo subtítulo do presente artigo, baseado principalmente no conceito de representações de Chartier (1990; 1991; 2002), e na literatura sobre a história e cultura Afro-Brasileira e Africana, parte do entendimento de que:

As representações não são discursos neutros, produzem estratégias e práticas tendentes a impor uma autoridade, uma referência, e mesmo legitimar escolhas. Ora, é certo que elas colocam-se no campo da concorrência e da luta. Nas lutas de representações tentam-

\footnotetext{
4 "Estereótipos são uma maneira de 'biologizar' as características de um grupo, isto é, considerá-las como fruto exclusivo da biologia, da anatomia. O processo de naturalização ou biologização das diferenças étnico-raciais, de gênero ou de orientação sexual, que marcou os séculos XIX e XX, vinculouse à restrição da cidadania a negros, mulheres e homossexuais" (BRASIL, 2009, p. 25). Contudo, HEILBORN et al (2010) acrescenta que os "[...] estereótipos foram criados em resposta a interesses hegemônicos, identificados com base na ideia de inferioridade, a qual se concretizou com os discursos da biologia e seu sofisticado desenvolvimento de sistemas classificatórios" (HEILBORN et al, 2010, p. 94).
} 
se impor a outro ou mesmo ao grupo sua concepção de mundo social, conflitos que são tão importantes quanto as lutas econômicas; são tão decisivas quanto menos imediatamente materiais. (CHARTIER, 1990, p. 17).

Dessa forma, as representações são entendidas como expressões das relações de poder e construções discursivas que tendem a manipular e legitimar contraditoriamente discursos que atendem a interesses de dominação e submissão previamente definidos. As representações não discursos desinteressados, ao contrário, tendem a impor intenções e concepções.

\section{Representações e história e cultura Afro- Brasileira e Africana}

É importante ressaltar que o conceito de representação no cotidiano da sociedade brasileira é muito pertinente, tendo em vista a grande diversidade étnico-racial, o que consequentemente gera conflitos e tensões na construção de representações de cada grupo étnico. Por sua vez há reflexo na organização didático-pedagógica das escolas, principalmente no que se refere ao objeto desta pesquisa: os trabalhos escolares produzidos em face do Dia Nacional da Consciência Negra.

A noção de "representação coletiva" permite articular as relações com o mundo social, desde as "configurações intelectuais múltiplas pelas quais a realidade é contraditoriamente construída pelos diferentes grupos que compõem uma sociedade", passando pelas práticas que constroem e fazem "reconhecer uma identidade social [...] exibir uma maneira própria de ser no mundo, [...] significar simbolicamente um estatuto e uma posição". (CHARTIER, 1991, p. 183).

Assim, as estratégias simbólicas reveladoras de "[...] práticas e representações culturais podem ser pensadas em relação às diferentes apropriações feitas por grupos sociais distintos ao longo do tempo" (DENIPOTI et al, 2009, p. 24).

Isso quer dizer que as representações sofrem interferências das relações de poder, pelas quais as estratégias simbólicas, sejam hegemônicas ou contrahegemônicas, são usadas para que a representação seja construída, e alcance ou não reconhecimento e legitimidade social, já que depende da força dos elementos simbólicos e da articulação dos coletivos envolvidos.

De uma perversão da relação de representação [...] Todas visam, com efeito, a fazer com que a coisa não tenha existência senão na imagem que a exibe, com que a representação mascare ao invés de designar adequadamente o que é seu referente. A relação de representação é assim turvada [...] que faz com que se tome o engodo pela verdade, que considera os sinais visíveis com indícios seguros de uma realidade que não existe. Assim desviada, a representação transforma-se em máquina de fabricar respeito e submissão, em um instrumento que produz uma imposição interiorizada, necessária lá onde falta o possível recurso à força bruta. (CHARTIER, 2002, p. 75).

Assim a representação pode mascarar uma ideia ao invés de designar o que é seu referente de fato. Pelas relações de poder existentes nas representações, aquelas identificadas nos trabalhos escolares da pesquisa podem retratar tanto 0 reconhecimento e a valorização da história e cultura Afro-Brasileira e Africana, como a discriminação, os estereótipos e o preconceito a respeito do tema.

Desse modo, a representação é "[...] vista como uma forma de conhecimento do Outro, a representação está no centro da conexão saberpoder" (SILVA, 2010, p.128). As representações são expressões das relações de poder, visto que elas carregam interesses de classes, grupos, etc. e, portanto, são capazes de mobilizar estratégias e ações que dão sustentação ao seu discurso, independentemente da correspondência com a realidade. Assim, no âmbito das representações e suas relações com o real, não se trata da mera oposição verdade versus falsidade.

Ainda que a representação comporte a exibição de elementos evocadores ou miméticos, sua força não é medida pelo seu valor de verdade, ou seja, da correspondência dos discursos e das imagens com o real. Ela se dá pela sua capacidade de mobilização e de produzir reconhecimento e legitimidade social. (PESAVENTO, 2004, p. 41).

Dessa forma, as representações podem ser impostas por aqueles que detêm o poder hegemônico 
de expandir tais representações, sejam elas pejorativas ou de valorização de determinados grupos. Estes, por sua vez, podem vir a desconstruir tais representações, o que pode ser compreendido como contranarrativas. Conforme as Diretrizes Curriculares da Educação Básica do Estado do Paraná para a área de História, "[...] a negação proposta por essas contranarrativas demarca os pontos de vista históricos e os distinguem das orientações de sentido histórico sustentadas por outros sujeitos" (PARANÁ, 2008, p. 59).

Seguindo esta mesma linha de pensamento:

[...] a marginalização da cultura afro-brasileira está visceralmente atrelada ao poder de enraizamento das verdades criadas pelos cânones da cultura europeizada, e como o pensamento identitário brasileiro utilizou desses conteúdos para buscar explicar a nação, silenciando vozes e determinando quais os discursos convenientes para a possível coesão do país e o silenciamento das vozes que se manifestaram e se manifestam com uma agenda anti-hegemonia. (JESUS, 2012, p.148).

Tendo em vista o exposto, o silenciamento das vozes marginalizadas foi 0 resultado do tensionamento inerente às relações de poder envolvidas, designando inclusive qual discurso ocupou o lugar da hegemonia por séculos da história brasileira. Porém, assim como as representações são construídas elas também estão sujeitas às desconstruções, elas mudam com o passar do tempo e com novas reivindicações e paradigmas.

A lei 10.639/03 parte da premissa de que a história e cultura Afro-Brasileira e Africana foram marginalizadas, daí este dispositivo legal ser considerado como uma das ações de reparação, reconhecimento e valorização da temática, e sua consequente inclusão no currículo escolar. Do mesmo modo, considera-se a partir deste estudo que o discurso da lei também é uma representação, e por isso mesmo é fundamental considerá-la neste estudo.

Art. 26-A. Nos estabelecimentos de ensino fundamental e médio, oficiais e particulares, torna-se obrigatório o ensino sobre História e Cultura Afro-Brasileira.

§ 10 O conteúdo programático a que se refere o caput deste artigo incluirá o estudo da
História da África e dos Africanos, a luta dos negros no Brasil, a cultura negra brasileira e o negro na formação da sociedade nacional, resgatando a contribuição do povo negro nas áreas social, econômica e política pertinentes à História do Brasil.

§ 20 Os conteúdos referentes à História e Cultura Afro-Brasileira serão ministrados no âmbito de todo o currículo escolar, em especial nas áreas de Educação Artística e de Literatura e História Brasileiras.

[...]

Art. 79-B. O calendário escolar incluirá o dia 20 de novembro como 'Dia Nacional da Consciência Negra'. (BRASIL, 2003).

A história e cultura Afro-Brasileira e Africana, antes da Lei 10 639/03, fruto de lutas e reivindicações do movimento negro brasileiro, eram tidas como esquecidas e negligenciadas no contexto social e educacional. A partir de então elas passaram a ser representadas de outro modo, principalmente no ambiente escolar. Contudo, “[...] o oposto de uma representação racista de uma determinada identidade racial não é simplesmente uma identidade 'verdadeira', mas uma outra representação feita a partir de outra posição enunciativa na hierarquia das relações de poder" (SILVA, 2010, p.103).

Desse modo, entende-se que as variadas representações de cunho étnico racial e cultural são então construções, permeadas inclusive pelo embate entre hegemonia e contra-hegemonia. Adota-se aqui o entendimento de que hegemonia "[...] pressupõe a conquista do consenso e da liderança cultural e político-ideológica de uma classe ou bloco de classes sobre as outras. Além de congregar as bases econômicas, a hegemonia tem a ver com entrechoques de percepções, juízos de valor e princípios entre sujeitos da ação política" (MORAES, 2010, p. 54). Por sua vez, parte-se também do entendimento de que a contra-hegemonia:

Institui o contraditório e a tensão no que até então parecia uníssono e estável. [...] Pode ser reelaborada, revertida e modificada, em um longo processo de lutas, contestações e vitórias cumulativas. [...] Significa reorientar as percepções sobre o mundo vivido e combater as racionalidades hegemônicas, vislumbrando o presente como passível de ser alterado por ações concatenadas e convincentes. Um dos desafios centrais para o pensamento contrahegemônico consiste em alargar a visibilidade pública de enfoques ideológicos que contribuam para a reorganização de 
repertórios, princípios, e variáveis de identificação e coesão, com vistas à alteração gradual e permanente das relações sociais e de poder. (MORAES, 2010, p. 73).

$E$, em se tratando de representações de alteridade, bem como materializadas neste trabalho em imagens e textos, cabe destacar:

A representação do outro pode ser mais uma maneira de manipular aquilo que se deseja [...]. As facetas das representações consistem em delegar poder de legitimidade a quem enuncia o discurso e consegue dar uma roupagem verídica e de grande valor discursivo na maior escala possível de irradiação. (JESUS, 2012, p.167).

Com as políticas afirmativas e de reconhecimento da história e cultura Afro-Brasileira e Africana, os discursos hegemônicos da classe branca europeia se tornaram cada vez mais alvos de embates e disputas, agora em torno de uma nova representação feita a partir de outro lugar de enunciação na hierarquia das relações de poder.

\section{O Dia Nacional da Consciência Negra e o contexto da produção dos trabalhos escolares: análise das fontes}

Os trabalhos escolares produzidos em face do Dia Nacional da Consciência Negra, e eleitos para esta pesquisa como fontes, são um interessante conjunto de imagens e textos, até mesmo porque compõem o produto final da ação didático-pedagógica da Equipe Multidisciplinar do Colégio, e em certa medida representam a concepção de ensino e aprendizagem adotada.

Os mesmos se encontram em arquivos digitais e pessoais da autora, professora pedagoga no Colégio Estadual do Campo Dr. Antonio Pereira Lima, localizado no Distrito Panema, município de Santa Mariana-PR, referentes ao período de 2013-2015. Vale dizer que o Colégio atende cerca de 250 alunos nos três turnos de funcionamento, cuja clientela é proveniente da citada comunidade, da zona rural e do distrito vizinho de Quinzopólis, sendo em sua maioria filhos de trabalhadores rurais e de agricultores.
De acordo com o Projeto Político Pedagógico (PPP) da instituição, "[...] além da função primordial de transmitir conhecimentos sistematizados, a escola tem a função de oferecer ao educando uma formação ética e moral" (PARANÁ, 2013, p.14). Sendo o PPP um documento que traduz a organização do trabalho didático pedagógico da escola, "[...] explicita uma filosofia e harmoniza as diretrizes da educação nacional com a realidade da escola, [...] definindo seu compromisso com a clientela" (VEIGA, 2005, p.110).

Desta forma, ao se considerar os embates e disputas em tornos das representações relativas à história e cultura Afro-Brasileira e Africana, um dos princípios didático-pedagógicos da instituição, expresso no PPP, aponta que:

[...] se de um lado a educação contribui para a reprodução da sociedade por meio da produção, da sistematização e da divulgação de uma ideologia, do outro, ela pode contribuir para a transformação da mesma sociedade através da produção, da sistematização e da divulgação de uma contra-ideologia. Ela pode proceder a uma crítica da ideologia vigente, desmascarando-a, denunciando seus compromissos com os interesses dos grupos dominantes no interior da sociedade e gerando, então, uma nova consciência social entre os sujeitos. (PARANÁ, 2013, p. 158).

Portanto, o principio didático-pedagógico destacado do PPP do Colégio Estadual do Campo Dr. Antonio Pereira Lima vem ao encontro das políticas educacionais e da legislação vigente ao propor a divulgação e sistematização de uma contra-ideologia. $\mathrm{Na}$ perspectiva desse estudo podemos tomar os trabalhos escolares classificados como representações anti-hegemônicas na mesma linha do referido princípio.

Ao analisar as fontes deste estudo, também utilizadas para a elaboração do Memorial Descritivo da Equipe Multidisciplinar da própria instituição, foi possível verificar as representações existentes em torno da história e cultura Afro-brasileira e Africana: sejam elas advindas do "sistema hegemônico branco e ocidentalizado" (primeiro grupo); ou de representações tidas como anti-hegemônicas (segundo grupo), por sua vez estabelecidas como 
uma nova representação, baseada em novos referenciais.

\section{Imagem 1: "Zumbi dos Palmares e o Dia Nacional da Consciência Negra", grupo 1.}

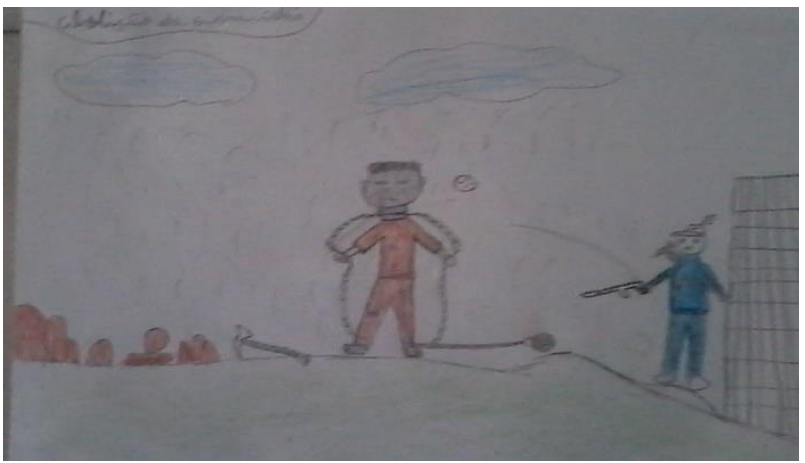

Fonte: Acervo da autora, 2015.

Pelo estudo da imagem 1, do grupo 1, verificase que a representação da história e cultura AfroBrasileira e Africana no Brasil ainda está atrelada aos contextos da escravidão e da expansão do capitalismo, sendo válido ponderar sobre o fato de que a história da África e dos africanos antes disso foi muito pouco considerada por nossa tradição historiográfica.

Pela análise da imagem 1 (grupo 1) podemos identificar a representação do negro enquanto escravizado e passivo diante dos castigos que eram impostos no sistema escravista, o que desencadeia a representação de um sujeito inferior e incapaz na ótica da classe dominante branca e europeia. De acordo com SILVA (2010, p.128), “[...] representação que o Ocidente, ao longo da trajetória de sua expansão colonial, construiu um 'Outro' como supostamente irracional e inferior".

Tendo em vista que as representações são construídas na teia da hierarquia das relações de poder, também a historiografia acadêmica, e por sua vez a historiografia escolar, disseminaram e fundamentaram tal entendimento.

O negro foi frequentemente associado na historiografia brasileira à condição social do escravo. A menção ao primeiro remete-se quase automaticamente à imagem do segundo. Negro e escravo foram vocábulos que assumiram conotações intercambiáveis, pois o primeiro equivalia a indivíduos sem autonomia e liberdade e o segundo correspondia - especialmente a partir do século XVIII - a indivíduo de cor. Para a historiografia tradicional, este binômio (negroescravo) significa um ser economicamente ativo, mas submetido ao sistema escravista, no qual as possibilidades de tornar-se sujeito histórico, tanto no sentido coletivo como particular do termo, foram quase nulas. (CORREA, 2000, p. 87).

Assim o negro era visto como um ser sem poder de reação e de autonomia, tornado mero objeto, com total dependência, ou seja, uma simples engrenagem do sistema colonial e escravista. Assim, "[...] o binômio branco/negro representou também livre/escravo, rico/pobre e uma série de outras adjetivações que qualificavam os grupos opostos. As diferenças culturais e físicas foram usadas como lógica da dominação criada ao longo de quase quatro séculos" (CERRI, 2007, p. 139). Este tipo de representação do negro está presente no meio escolar mesmo após a promulgação da Lei 10.639/03, o que mostra que as relações de poder envolvidas nas representações são difíceis de serem desconstruídas.

A imagem 2, grupo 1, retrata a miscigenação da população brasileira no tripé índios, negros e brancos, com o propósito de apontar a miscigenação e a mistura de raças como algo positivo dentro da sociedade brasileira. Porém, essa ideia trata de um mito atualmente conhecido, o "mito da democracia racial”. Souza (1983, p.25) afirma que "[...] enquanto produto econômico político-ideológico, o mito é um conjunto de representações que expressa e oculta uma ordem de produção de bens de dominação e doutrinação".

\section{Imagem 2: "Miscigenação de raças e o mito da} democracia racial", grupo 1.

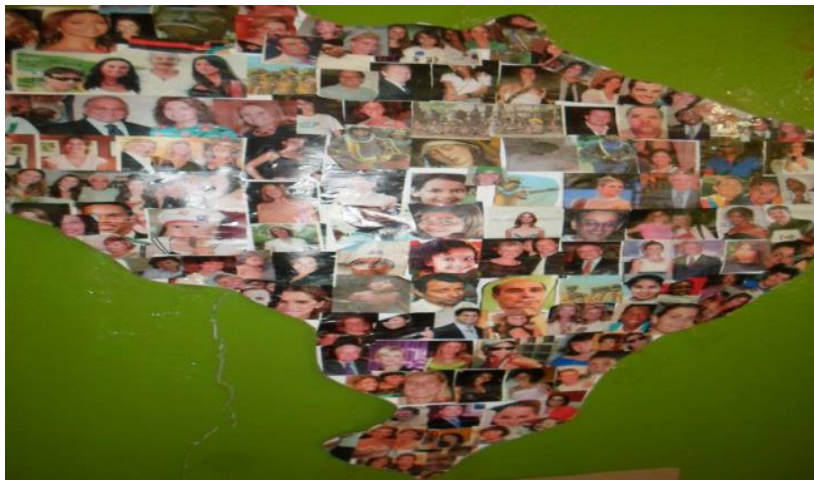

Fonte: Acervo da autora, 2013. 
Para a realidade brasileira, por sua vez, tratase de um mito porque não havia e ainda não há uma situação de equidade social, racial e de direitos no Brasil, pelo contrário, serve para camuflar as injustiças sociais, racismo e preconceito.

De acordo com Krauss e Rosa (2010, p. 869),

Construiu-se ideologicamente um discurso que prega a existência da harmonia racial entre brancos e negros, desviando o olhar da população e do Estado brasileiro das crueldades cometidas contra os africanos e afrodescendentes escravizados no Brasil, impedindo-os de agirem de forma incisiva e eficaz contra as manifestações racistas. Esse discurso é chamado de democracia racial.

A representação negativa do negro, a partir de estereótipos e da discriminação é decorrente das teorias raciais existentes e disseminadas também no Brasil no século XIX, como o etnocentrismo, o racismo científico e o Darwinismo Social ${ }^{5}$.

No contexto brasileiro do século XIX havia por parte das elites nacionais o desejo de construção da identidade brasileira alinhada com os padrões de progresso da Europa. "Afirmavam que os africanos e seus descendentes seriam incapazes de interiorizar sentimentos civilizados sem que antes as virtudes étnicas dos trabalhadores brancos se impregnassem, com os cruzamentos inter-raciais" (AZEVEDO, 1987, p.53).

Gilberto Freyre, sociólogo brasileiro, foi um dos disseminadores do mito da democracia racial. No Brasil, a ideia de degeneração racial a partir da mestiçagem foi substituída pela lógica de uma mestiçagem melhorada, o que ocorreria justamente pela sobreposição das características vistas como positivas e da raça branca, sobre aquelas encaradas

\footnotetext{
5 De acordo com Schmidt (2002, p. 242 apud OLIVA, 2007, p. 297), "[...] o etnocentrismo baseia-se na falsa ideia de que existem povos culturalmente superiores e povos culturalmente inferiores. [...] Outra ideia que surgiu para defender o imperialismo foi o racismo". Na junção de ambas, ganhava força e contornos práticos "[...] a tese de que a raça branca era superior às outras raças e que, portanto, merecia dominar o planeta. Os asiáticos, os índios e os africanos tinham de ser dominados porque eram 'menos inteligentes' e 'menos saudáveis' que a 'raça branca'” (SCHMIDT, 2002, p. 242 apud OLIVA, 2007, p. 297). Por sua vez, com base no chamado darwinismo social, o domínio imperialista nada mais era do que a confirmação da lei biológica da sobrevivência dos mais fortes: os países com um povo 'mais competente' e 'mais trabalhador' mereciam submeter os outros" (SCHMIDT, 2002, p. 242 apud OLIVA, 2007, p. 297).
}

como negativas e provenientes das raças negra e indígena. Ao escrever Casa Grande \& Senzala (1933), Freyre forjou ideologicamente o discurso de que a riqueza de nossa cultura é a diversidade, resultante da miscigenação de raças, por sua vez retratada de forma harmoniosa e equilibrada, e desconsiderando as situações concretas de domínio, exploração e dominação no contexto da formação da sociedade brasileira. Assim o "[...] mito das três raças torna-se então plausível e pode-se atualizar como ritual" (ORTIZ, 2006, p. 41).

Então, ocorreu no Brasil uma política de incentivo à imigração, com o propósito de "branquear, civilizar e de elevar o nível social da população". Para Freyre (2003, p. 33) “[...] a miscigenação que largamente se praticou aqui corrigiu a distância social que de outro modo se teria conservado enorme entre a casa-grande e a mata tropical; entre a casa-grande e a senzala". A miscigenação de pretensas raças, base de uma democracia racial a ser construída no Brasil, na realidade se constituía "[...] como um campo fértil para a perpetuação de estereótipos sobre negros, negando o racismo no Brasil, mas, simultaneamente, reforçando as discriminações e desigualdades raciais" (GOMES, 2005, p. 57).

Não temos aqui a pretensão de negar a miscigenação como processo constituinte e constituído na sociedade brasileira, porém, não podemos deixar de mencionar que a representação existente na imagem 2 (grupo 1) está pautada numa visão ingênua e mítica sobre a democracia racial no Brasil. A falaciosa ideia de mistura harmoniosa é assim descrita por Freyre (2003, p. 160):

Híbrida desde o início, a sociedade brasileira é de todas da América a que se constituiu mais harmoniosamente quanto às relações de raça: dentro de um ambiente de quase reciprocidade cultural, que resultou no máximo de aproveitamento dos valores e experiências dos povos atrasados pelo adiantado, no máximo de contemporização da cultura adventícia com a nativa, da do conquistador com a do conquistado. (FREYRE, 2003, p. 160).

O mito da democracia racial representado na imagem 2 (grupo 1) como algo positivo e processado equitativo e pacificamente na sociedade brasileira, 
mascara o histórico à que foram subjugados os negros no Brasil. Isso porque esse mito não considera que a miscigenação foi "[...] construída a partir da dominação, colonização e violência, sobretudo, de uma profunda violência sexual dos homens brancos em relação às mulheres negras e indígenas. E mais, [...] qualquer forma de dominação e violência é perversa" (GOMES, 2005, p. 58).

É preciso ter consciência de que o mito da democracia racial foi forjado no país através de mecanismos ideológicos, políticos e culturais, e que é preciso superar e romper com este mito principalmente no meio escolar, uma vez que camufla as desigualdades e injustiças sociais e raciais no país.

Imagem 3: "África negra, exótica e pobre”, grupo 1.

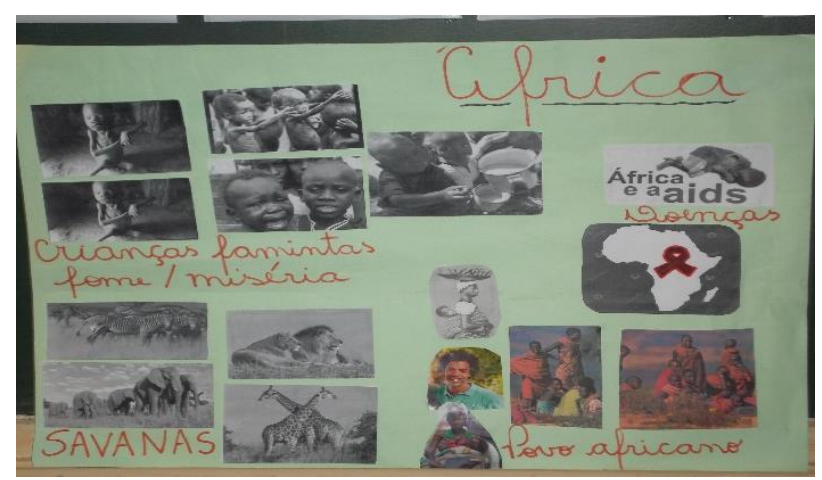

Fonte: Acervo da autora, 2014.

$\mathrm{Na}$ imagem 3, do grupo 1, podemos verificar o continente africano representado pela natureza selvagem e ambientes exóticos das savanas, florestas tropicais e desertos. São destacados os locais povoados por crianças famintas, que vivem na miséria, além da presença de doenças como a AIDS. Há também uma identificação do continente como local habitado somente por negros, desconsiderando as diferentes etnias, cores e raças existentes no continente africano.

Apesar de a cultura negra ser a energia que dá ritmo à vida nacional, considerando ainda a dívida imensa do Brasil para com a África, não se observa uma equivalência desses pesos na vida e na política. Não é exagero considerar um escândalo a ignorância em relação à África. [...] a grande maioria dos brasileiros considera o continente africano como um bloco homogêneo: tudo igual e todos negros. Quando muito, separam a África do norte, que é árabe, daquela situada abaixo do deserto do Saara, também chamada África Negra. (SANTOS, 2001, p. 247).

A representação que se efetiva do continente africano na imagem 3 (grupo 1) desconsidera a diversidade étnico-racial, suas riquezas, seus conhecimentos, o que não contribui com a desconstrução de estereótipos que circunscrevem o continente africano. Este desconhecimento do continente africano acarreta consequências drásticas quanto à forma com que o mesmo é representando. "Este mundo, ainda crivado de exotismo e superstição, seria um fomentador de rituais e crenças ilógicas que arrastariam a matriz africana para longe de qualquer plausibilidade científica" (FLORES, 2006, p. 68).

De acordo com Oliva (2007) não é preciso se distanciar muito no tempo para reconhecermos as limitações e imperfeições de nossas referências e ideias acerca da África. Atualmente ainda persistem imagens que a África e os africanos se confundem com velhos e resistentes estereótipos: regiões e pessoas marcadas pela miséria, pelas doenças, pelos conflitos étnicos, pela instabilidade política, pela AIDS, pela fome, pela falência econômica.

Considerando as representações em que a África não é considerada na sua diversidade, mas apenas pelo viés etnocêntrico, branco e ocidentalizado, ou seja, pelas representações hegemônicas, não estamos dizendo que devemos esconder ou mascarar as realidades trágicas ali encontradas, mas que nosso olhar não se reduza a elas. Em nome dos interesses imperialistas o povo africano foi dominado e o continente explorado em suas riquezas, já que nessa perspectiva,

Os africanos seriam incapazes, portanto, de qualquer criação ou invenção que possibilitasse transformações em suas realidades ou exigissem conhecimentos "complexos". Mesmo com a "descoberta" nas primeiras décadas do século XX, em África, de complexas elaborações nos campos da arte estatuária da produção agrícola, da arquitetura, das organizações sociais e do pensamento, a afirmativa inferioridade africana foi mantida. (OLIVA, 2007, p.72). 
Por fim, a imagem 4, do grupo 1, traz os dizeres: "20 de novembro é o Dia da Consciência Negra". No entanto, temos a imagem de um negro escravizado com a corrente arrebentada, em referência à lei de Abolição da escravatura no Brasil. A imagem não faz referência à abolição da escravização dos negros como uma conquista por meio dos atos de resistência negra e escrava. É possível perceber isso pelo rompimento da corrente sendo retratado como acontecimento repentino, sem causa aparente, e acompanhado da reação de surpresa do personagem do desenho. A imagem em questão, frequentemente encontrada em livros paradidáticos ilustrados sobre datas comemorativas, pode reforçar a visão tão fartamente divulgada no meio escolar por décadas, pela qual a Princesa Isabel por bondade e compaixão decretou a abolição da escravatura. Essa versão ignora os fatos e processos históricos daquele contexto brasileiro de fim do século XIX e a própria ação dos negros escravizados neste sentido.

Imagem 4: “Abolição da escravatura”, grupo 1.

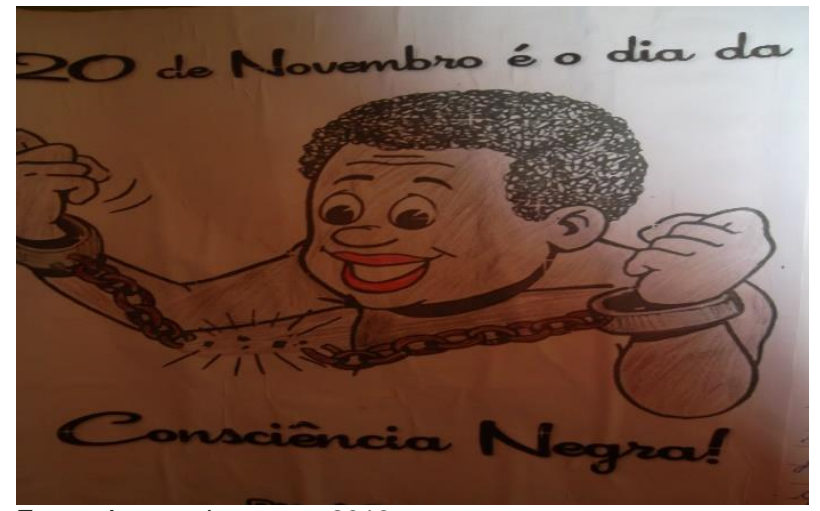

Fonte: Acervo da autora, 2013.

De acordo com Albuquerque (2006), há a construção da imagem paternalista da "raça emancipada" pela "raça emancipadora", ainda que parte do discurso abolicionista "branco" tenha sido contestada com versões que não partiam da passividade dos negros, mas da luta abolicionista. Assim, os sentidos da Abolição poderiam ser múltiplos e eram certamente conflitantes.

Tendo em vista as relações de dominação e resistência, e a compreensão de que os diferentes sujeitos são participantes ativos do processo histórico, é possível pensar as estratégias de resistência, reação e negociação dos negros escravizados, que contrariam uma ideia de libertação dada de "mão beijada" pela Princesa Isabel.

"Todas as práticas sejam elas econômicas ou culturais dependem das representações utilizadas pelos indivíduos para darem sentido ao seu mundo" (HUNT, 2001, p. 25). A maneira com que os indivíduos compreendem e percebem a si mesmos e aos outros condiciona a sua representação. Assim, a representação do negro por si mesmo tem se transformado também, até mesmo pelo processo de redemocratização, e mais recentemente com a Lei 10.639/03. Por isso a própria escola tem criticado gradativamente representações pejorativas, as quais vêm sendo substituídas por outras representações de cunho valorativo, o que possibilita a emersão de um novo mote que tematiza as relações raciais, sobretudo no campo educacional.

Portanto, a partir de então são analisados os trabalhos escolares do grupo 2, os quais apresentam representações entendidas como anti-hegemônicas, ou seja, na linha oposta ao grupo 1, e que valorizam a diversidade étnico-racial afro-brasileira e africana, e reconhecem a contribuição cultural, social e econômica dos negros à sociedade brasileira.

A imagem 1, do grupo 2, apresenta com nitidez os processos de disputa ligados às representações que retratam a história e cultura Afro-Brasileira e Africana.

Imagem 1: "Zumbi dos Palmares e o Dia Nacional da Consciência Negra”, grupo 2.

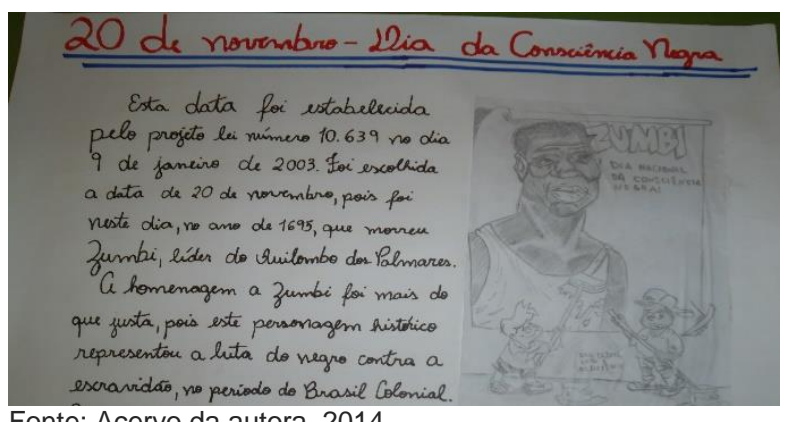

Fonte: Acervo da autora, 2014.

O próprio discurso de que o Dia Nacional da Consciência Negra foi escolhido em razão da data de morte de Zumbi dos Palmares, e de que foi uma 
homenagem a este personagem histórico que representa a luta do negro contra a escravidão no Brasil Colonial, é uma representação antihegemônica, conforme já apontado ${ }^{6}$. Isso porque o que anteriormente era tido como "dominado e inferior", ao menos na ótica dominante, etnocêntrica e eurocêntrica, agora passa a reivindicar a sua valorização e reconhecimento, que por sua vez se reflete em nova representação.

A imagem 2, do grupo 2, descreve as formas de resistências escravas, o que contraria a representação discriminatória e estereotipada que foi construída pela classe dominante branca e escravista no Brasil ao longo dos trezentos anos do regime escravocrata.

Durante muito tempo a figura do escravizado esteve marcada como mero objeto do sistema escravista, sendo vistos como sujeitos dóceis e passivos, enfim como mercadoria, pois assim estariam impossibilitados de qualquer reação. Porém, Reis e Silva (1989) afirmam que a sociedade escravista foi marcada pela negociação, rebeldia e resistência escrava, o que contraria a ideia de submissão passiva dos escravizados. "A fuga era a forma de resistência mais radical, e sua simples possibilidade marca os limites da dominação. Havia as fugas reivindicatórias e as fugas de rompimento. $A$ formação de quilombos e as rebeliões eram as principais formas de resistência escrava coletiva" (SZESZ et al, 2011, p. 47).

\section{Imagem 2: “Resistências Escravas”, grupo 2.}

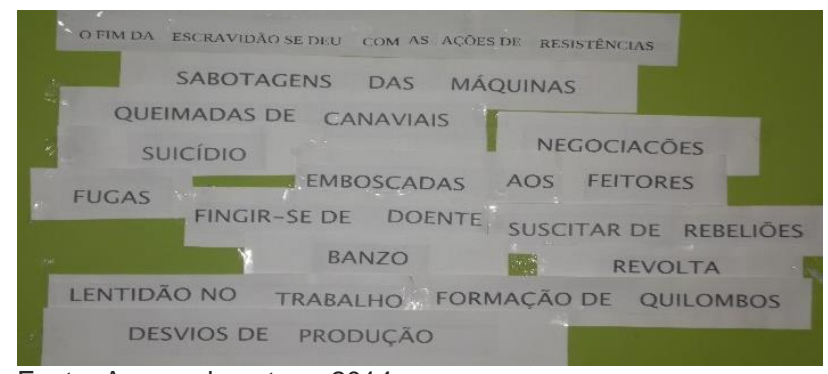

Fonte: Acervo da autora, 2014.

\footnotetext{
6 No texto do cartaz evidenciado na imagem 1, do grupo 2, há uma informação equivocada quanto à lei que instituiu a data do Dia Nacional da Consciência Negra. A referida data, então denominada Dia Nacional de Zumbi e da Consciência Negra foi estabelecida somente pela Lei no. 12.519, de 10 de novembro de 2011. Contudo, desde a promulgação da Lei 10.639/2003, a mencionada data já fazia parte do calendário escolar de comemorações.
}

A temática da resistência escrava ganhou força na historiografia brasileira a partir de 1980 quando Reis e Silva (1989) começaram a estudar este tema propondo dois importantes conceitos para entender esta questão: negociação e conflito.

Na sua maioria, as negociações dos escravos com os seus senhores eram forçadas pelos próprios escravos. Segundo Reis (1989), no Brasil os escravos mais negociaram as condições de escravidão do que lutaram abertamente contra o sistema. Para melhor compreendermos essa questão, basta citar as sabotagens que ocorriam nos engenhos. Ou seja, nem sempre os proprietários de escravos conseguiam impor suas vontades. $\mathrm{O}$ engenho dependia de uma técnica complexa e, muitas vezes, para não ser alvo de sabotagens, o proprietário negociava com seus escravos. A negociação englobava, por exemplo, o direito de folga nos finais de semana, a permissão para o escravo cultuar de forma livre a sua religião e para cultivar sua própria horta. Eram também negociadas condições para transportar e revender produtos na cidade. (SZESZ et al, 2011, p. 39).

Podemos apontar que a imagem 2 (grupo 2) apresenta uma representação anti-hegemônica quanto à escravidão no Brasil, ao considerar que os escravizados se opuseram à escravidão por meio de diversas formas de resistência. Dessa forma, torna-se possível uma representação que visa a desconstrução da representação do escravizado enquanto sujeito passivo e submisso diante do sistema escravista.

A imagem 3 , do grupo 2 , retrata a seguinte questão: "continente africano: invisível ou invisibilizado?"

\section{Imagem 3: “(in)visibilidade do Continente} Africano", grupo 2.

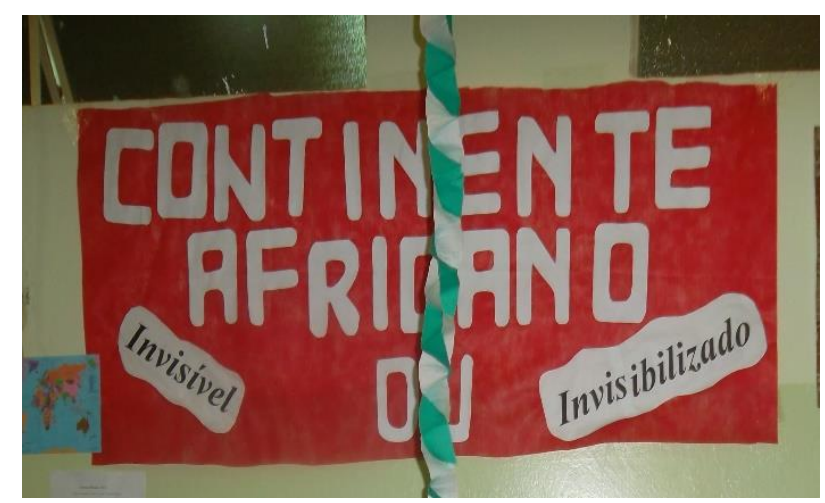

Fonte: Acervo da autora, 2013. 
A partir do questionamento do cartaz podemos perceber a arena de embates e disputas em torno da história e cultura Afro-brasileira e Africana. Só o fato de fazer esta pergunta aos possíveis leitores do cartaz parece considerar que o continente africano, a sua história, a sua cultura, o seu povo não é invisível, mas que há interesses que fazem com que seja invisibilizado, esquecido e discriminado perante o mundo.

Conforme Jesus (2012, p. 168) coloca "[...] esse contato que temos com as representações estabelecidas, é capaz de moldar identidades e de prescrever o que é aceitável ou não na sociedade. Estes juízos de valor prejudicam uns e beneficiam outros, automaticamente".

Assim as representações podem (des) fazer discursos através de seu poder de enunciá-lo como verdadeiro e fiel, se constituindo em uma forma de manipulação do discurso. Diante desta característica das representações, Ribeiro (2015, p. 109), escreve que:

A emergência da Lei 10.639/03 [...] tem a potencialidade de "quebrar" os conteúdos, narrativas e temporalidades consagradas do ensino e da pesquisa histórica vinculados ao modelo "quadripartite" eurocentrado (História Antiga, História Medieval, História Moderna e História Contemporânea) do currículo escolar. Significa romper a narrativa consagrada acerca da nossa formação como país e nação pautada no protagonismo europeu. [...] A lei evidencia a necessidade urgente de se "descolonizar" a educação escolar brasileira, algo que vai além da própria disciplina de História.

Dessa forma, também o currículo assumiria uma perspectiva pós-colonial, voltada para uma análise crítica acerca das representações das relações entre culturas dominantes e dominadas, pois

[...] devem-se questionar os discursos, os saberes, as representações: quais visões são autorizadas e legitimadas? De quais grupos? Quais visões não estão representadas, mal representadas ou são representadas como déficit, carência ou exotismo? Quais visões são desautorizadas e deslegitimadas? Que relações de poder sustentam essas respectivas visões? (SILVA, 1995, p. 194 apud RIBEIRO, 2015, p. 113).
Por sua vez, a representação anti-hegemônica existente na imagem 4 retrata dois aspectos interessantes: o primeiro refere-se à presença de miniaturas das pirâmides do Egito, uma das "sete maravilhas do mundo", destacadas como situadas no continente africano; e o segundo ao reconhecimento da África como um continente, tendo em vista o estereótipo da África como um país.

\section{Imagem 4: "Pirâmides do Egito e África como continente e não país", grupo 2.}

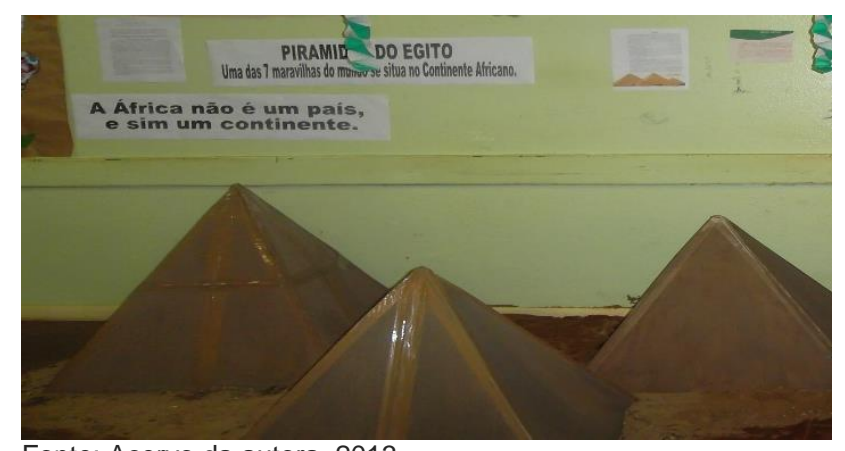

Fonte: Acervo da autora, 2013.

Em relação ao primeiro aspecto, Oliva (2009, p. 210) coloca que "[...] há uma perspectiva de alocar a civilização egípcia fora do continente negro, relacionando-a muito mais com as civilizações e sociedades do Oriente Próximo e da Europa Mediterrânea". A existência de representações em trabalhos escolares que retratam a civilização egípcia fora do continente africano tem consequências sérias. "Esse enfoque em nada auxilia a (des) construção do imaginário preconceituoso e deturpado que circula na mídia e em nossas referências mentais sobre a história da África" (OLIVA, 2009, p. 205).

Quanto ao estereótipo da África em ser tratada como um país e não como um continente, Gentile (2005, p. 44) aponta o seguinte: “[...] essa afirmação pode parecer absurda, mas não é. Há uma tendência em falar da África como se todos que ali vivem tivessem os mesmos hábitos e tradições". A representação da África como um país desconsiderando os diferentes povos, culturas e histórias existentes no continente contribuem com a manutenção do predomínio de uma história eurocêntrica, que coloca a Europa enquanto povo civilizado e superior aos demais. 
É necessário descrever a identidade desses sujeitos e a identidade desses locais, caso contrário, estaremos trilhando outro caminho que chegará a homogeneização. E aqui reside a importância desse exercício de identificação, pois nesse processo os alunos reconhecerão que se trata de um espaço composto de povos e culturas distintas. [...] A crítica à homogeneização da história do continente e a abordagem dessa história a partir de temas que nos levam a preservar a imagem de um território engolido pela pobreza e conflitos internos. (RIBEIRO, 2015, p.118).

Isso nos leva à imagem 5, grupo 2, que traz a representação da África em uma perspectiva de passado ancestral comum à humanidade.

\section{Imagem 5: "África como berço da humanidade e do conhecimento", grupo 2.}

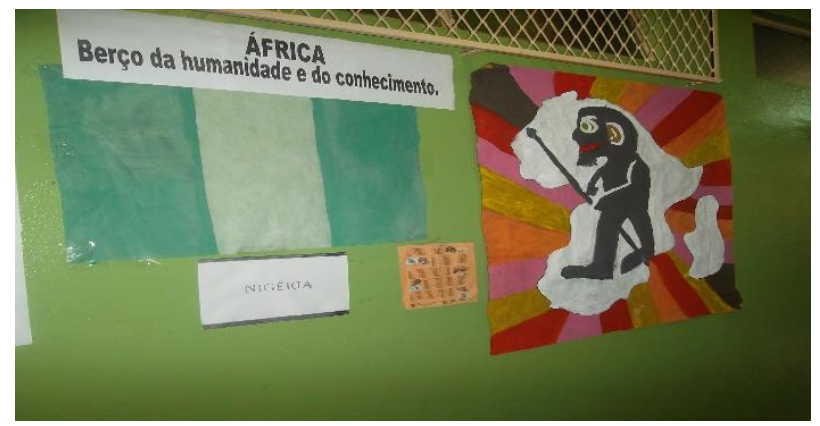

Fonte: Acervo da autora, 2014.

O texto da imagem 5 problematiza alguns pontos importantes, como: o continente africano enquanto local de origem dos seres humanos; a existência de uma África inventiva e pensante antes da investida dos europeus em busca de escravizados; e inclusive a coexistência de povos e civilizações por boa parte da Europa, África e Oriente em períodos da antiguidade. Além disso, o questionamento à suposta superioridade branca propagada pelas teorias raciais do século XIX. De acordo com Oliva (2009, p. 207)

Um dos equívocos mais comuns encontrados é o de fazer referência à África apenas a partir do tráfico de escravos para a América do século XVI em diante. Seria como se o continente não tivesse uma história anterior à escravidão atlântica. Nesses casos, [...] as diversidades e complexidades das sociedades africanas são, dessa forma, ignoradas.

Portanto, verifica-se na imagem 5 (grupo 2) uma representação anti-hegemônica da África, já que o continente africano não é retratado pela escravidão, por preconceitos ou estereótipos que o desqualificam, mas sim como produtor e difusor de conhecimento, retratando assim o reconhecimento e valorização da história e cultura Afro-Brasileira e Africana, conforme determina a Lei 10 639/03.

A história da África [...] remonta os primeiros passos da humanidade, à criação das primeiras formas gregárias de vida dos humanos e sua interação com a natureza. Migrações, descobertas, conhecimentos técnicos tiveram presentes nas histórias mais remota dos grupos humanos que viveram no continente africano. (LIMA, 2009, p. 158 apud RIBEIRO, 2015, p. 109).

De um lugar marcado por estereótipos, estigmas e pelo esquecimento a imagem da África foi ganhando um imaginário marcado pela positividade, como berço da humanidade e do conhecimento.

[...] o conjunto de perspectivas criado pelos vestígios arqueológicos, históricos e paleoantropológicos que chegavam do passado ao conhecimento de todos, pelas teses da anterioridade humana e civilizacional em África e pela defesa da ideia de que a raça negra deveria ser pensada pelas suas qualidades e elementos em comum, foi usado para evidenciar as qualidades inegáveis das populações africanas. Esses mesmos elementos estiveram no centro dos esforços de redefinição da auto-imagem do africano e da imagem que se projetava do continente pelo mundo. (OLIVA, 2007, p.77).

O fato de a África ser representada como uma nova perspectiva de um passado grandioso teve importantes repercussões que refletiram não só na África, mas também nas Américas.

[...] a influência dessas teses principalmente a da "anterioridade das civilizações em África" viu-se refletida na criação de uma série de movimentos sociais e políticos organizados que lutavam pela conquista de direitos para a população afro-descendente, pela criação de sociedades baseadas na igualdade racial e econômica e, muitas vezes, por políticas afirmativas e de reparação pelas múltiplas marcas deixadas pela escravidão e pelo racismo. (OLIVA, 2007, p.78).

Os sujeitos até então discriminados, esquecidos e retratados com estereótipos que os desqualificavam e ao mesmo tempo exaltavam exclusivamente a cultura branca europeia, passaram a ter visibilidade na História, permitindo assim que os 
"figurantes mudos" tivessem também o seu espaço como protagonistas.

\section{Considerações finais}

$\mathrm{Na}$ medida em que foi identificada a possibilidade de dividir os trabalhos escolares em dois grupos, no caso aquele associado às representações do sistema hegemônico (branco e ocidentalizado) e aquele relativo às representações anti-hegemônicas (importância da história e cultura Africana e Afro-brasileira), ficou claro que o ambiente escolar e suas correspondentes práticas pedagógicas ainda são terreno de disputa.

Por sua vez, a dimensão das representações revelou-se a cada passo como um caminho teórico realmente viável para a pesquisa, pois não se trata de julgar as concepções que os grupos de fontes revelaram, mas reconhecer seus elementos constituidores enquanto partes de entendimentos historicamente construídos, e consequentemente difundidos, inclusive nas escolas.

Desse modo, os paralelos entre as representações que descrevem a discriminação, estigmas e estereótipos da história e cultura AfroBrasileira e Africana, e aquelas que ressaltam 0 reconhecimento e a valorização da diversidade cultural revelaram-se muitas vezes tênues, porém fundamentalmente ancorados em concepções opostas. Isso quer dizer que não é possível garantir que os processos de disputa, imposição e negação ligados à história e cultura Africana e Afro-Brasileira estejam necessariamente tão bem resolvidos entre os sujeitos produtores dos trabalhos escolares tanto quanto suas representações nos trabalhos possam parecer.

As representações retratadas nos textos e imagens que compuseram as fontes selecionadas passaram por crivos pedagógicos e históricos, tanto de estudantes como de professores, seja no âmbito do que se entende por "politicamente correto" como pelo aspecto do que é curricularmente esperado. Por sua vez, nas representações verificaram-se ainda os silenciamentos e discursos amenizadores sobre a história e cultura Africana e Afro-Brasileira, os quais foram então encarados como conteúdo dos processos de negociação, conflitos e tensões entre o padrão cultural negro e africano e o padrão branco europeu, inclusive na dinâmica pedagógica escolar.

Uma vez que as representações, na esteira dos estudos de Chartier (1990; 1991; 2002), são entendidas como estratégias e práticas de tensionamento em meio às relações de poder, ferramentas como a Lei 10 639/03, que inseriu o ensino de história e cultura Afro-Brasileira e Africana nas escolas, vêm influenciando substancialmente a construção de representações sobre a temática, pelo menos no espaço escolar. Todavia, os veículos de disseminação dos discursos interessados em manter a lógica hegemônica vigente, entre os quais muitas vezes a própria escola enfileirou-se, também atuam para legitimar suas enunciações, cada qual tensionando a partir de suas intenções, interesses e concepções acerca do tema.

O longo processo de escravização, exploração e dominação política e ideológica que o "sistema hegemônico branco e ocidentalizado" impôs aos povos africanos e afro-descendentes fez com que a sua história e cultura fossem renegadas ao esquecimento, negligenciando e retratando-as como inferiores e incapazes. Essa realidade, a partir do que encontramos nas representações dos trabalhos do grupo 2, vem se alterando gradativamente, o que deve ser honestamente associado às reivindicações do Movimento Negro.

"Com efeito, a história da África, como a de toda a humanidade, é a história de uma tomada de consciência. Nesse sentido, a história da África deve ser reescrita. $\mathrm{E}$ isso porque, até o presente momento, ela foi mascarada, camuflada, desfigurada, mutilada" (KI-ZERBO, 1982, p. 21). É preciso que a reescrita da História da África e dos afro-descendentes se justifique por si só e a partir da sua própria história, suas invenções e descobertas, sua diversidade étnico-racial, linguagens, e contribuições para a humanidade.

Em suma, os embates e disputas entre as representações hegemônicas e anti-hegemônicas 
aqui retratadas nos dois grupos de trabalhos escolares, e em meio às relações de poder que lhes dizem respeito, demonstraram os interesses antagônicos e na maioria das vezes conflitantes, que por meio das representações tendem a impor intenções e concepções. Portanto, reafirma-se a necessidade de reconhecermos que a história da África, dos africanos, afro-brasileiros e afrodescendentes de modo geral, não pode se resumir a generalizações e homogeneizações, sendo assim necessário descolonizar o saber a respeito da temática, e assim visualizar para além de uma guerra entre narrativas, com vistas a uma convivência respeitosa entre as culturas.

\section{Referências}

ALBUQUERQUE, W. R. de. Uma história do negro no Brasil. Salvador: Centro de Estudos AfroOrientais. Brasília: Fundação Cultural Palmares, 2006.

AZEVEDO, C. M. M. de. Onda Negra Medo Branco: o negro no imaginário das elites-Século XIX. Rio de Janeiro: Paz e Terra, 1987.

BRASIL. Lei n.10.639, de 9 de janeiro de 2003. Altera a Lei $n^{\circ}$ 9.394, de 20 de dezembro de 1996, que estabelece as diretrizes e bases da educação nacional, para incluir no currículo oficial da Rede de Ensino a obrigatoriedade da temática "História e Cultura Afro-Brasileira", e dá outras providências. Brasília: Diário Oficial da União, 2003.

BRASIL. CNE/MEC. Resolução nํ. 1, de 17 de junho de 2004. Institui Diretrizes Curriculares Nacionais para a Educação das Relações Étnico-Raciais e para o Ensino de História e Cultura Afro- Brasileira e Africana. Brasília: Diário Oficial da União, 2004.

BRASIL. Ministério da Educação. Gênero e diversidade na escola: formação de professoras(es) em gênero, orientação sexual e relações étnico-raciais. Rio de Janeiro: CEPESC, Brasília: SPM, 2009.

HEILBORN, Maria Luiza. et al (org). Gestão de Políticas Públicas em Gênero e Raça/GPPGeR: módulo II. Rio de Janeiro: CEPESC; Brasília: Secretaria de Políticas Públicas para as Mulheres, 2010.

CHARTIER, R. O mundo como representação. Estudos Avançados, São Paulo, v. 5, n. 11, jan./abr. 1991
CHARTIER, R. Introdução. Por uma sociologia histórica das práticas culturais. In: _.. A História Cultural entre práticas e representações. Col. Memória e sociedade. Trad. Maria Manuela Galhardo. Rio de Janeiro: Bertrand Brasil, 1990, p. 13-28.

CHARTIER, R. A beira da falésia. Porto Alegre: Ed. Universidade UFGRS, 2002.

CERRI, L. F. (org.). Ensino de história e educação: olhares em convergência. Ponta Grossa: UEPG, 2007.

CORREA, S. M. de S. O negro e a historiografia brasileira. Revista Ágora, Santa Cruz do Sul, n. $1,2000$.

DENIPOTI, C. et al. História, Arte e Cultura. Ponta Grossa: EPG/NUTEAD, 2009.

FREYRE, G. Casa-grande \& senzala: formação da família brasileira sob o regime da economia patriarcal. São Paulo: Global, 2003.

FLORES, E. C. Etnicidade e ensino de História: a matriz cultural africana. Tempo, v. 11, n. 21, p. 65-8, 2006.

GENTILE, P. África de todos nós. In: Revista Nova Escola, São Paulo, ano XX, ed. 187, novembro, p. 44, 2005.

GOMES, N. L. Alguns termos e conceitos presentes no debate sobre relações raciais no Brasil: uma breve discussão. In: BRASIL. MEC. Secretaria de Educação Continuada, Alfabetização e Diversidade. Educação antiracista: caminhos abertos pela Lei Federal nํ. 10 639/03. Brasília: 2005.

HUNT, L. Apresentação: história, cultura e texto. In: HUNT, L. (org.) A. Nova História Cultural. 2 ed. São Paulo: Martins Fontes, 2001.

KRAUSS, J. S; ROSA, J. C. da. A importância da temática de História e Cultura Africana e Afrobrasileira nas escolas. Antíteses, v. 3, n. 6, p. 857-878, jul./dez. 2010.

KI-ZERBO, J. (Ed.). História Geral da África. Volume I. Metodologia e pré-história da África. São Paulo: Ática, 1982.

JESUS, F. S. de. O "negro" no livro didático de História do Ensino Médio e a Lei 10.639/03. História \& Ensino. Revista do Laboratório de Ensino de História/UEL, Londrina, v. 18, n. 1, p.141-171, jan/jun. 2012

MORAES, D. de. Comunicação, hegemonia e contrahegemonia: a contribuição teórica de Gramsci. Revista Debates, Porto Alegre, v. 4, n. 1, p. 5477, jan./jun. 2010. 
MUNANGA, K. Uma abordagem conceitual das noções de raca, racismo, identidade e etnia. $3^{\circ}$ Seminário Nacional Relações Raciais e Educação-PENESB. Rio de Janeiro: Geledes, 2013. Disponível em: <http://www.geledes.org.br/wpcontent/uploads/2014/04/Uma-abordagemconceitual-das-nocoes-de-raca-racismodentidade-e-etnia.pdf> Acesso em: 30 de Junho de 2016.

OLIVA, A. R. de. Lições sobre a África: Diálogos entre as representações dos africanos no imaginário Ocidental e o ensino de história da áfrica no Mundo Atlântico (1990-2005). Brasília: Universidade de Brasília, 2007.

OLIVA, A. R. de. O que as lições de história ensinam sobre a África? Reflexões acerca das representações da história da África e dos africanos nos manuais escolares brasileiros e portugueses. Revista Solta a Voz, Goiás, v. 20, n. 2, p. 197-214, 2009.

ORTIZ, R. Cultura brasileira e identidade nacional. São Paulo: Brasiliense, 2006.

PARANÁ. Colégio Estadual do Campo Dr. Antonio Pereira Lima. Projeto Político Pedagógico. Santa Mariana, 2013.

PARANÁ. Secretaria de Estado da Educação. Diretrizes Curriculares da Educação Básica História. Curitiba: SEED, 2008.

PESAVENTO, S. J. História \& História Cultural. Belo Horizonte: Autêntica, 2004.

REIS, J. J. \& SILVA, E. Negociação e conflito: a resistência negra no Brasil escravista. São Paulo: Cia. Das Letras, 1989.

RIBEIRO, R. et al. História da África no Ensino Superior: Imagens e Representações dos Estudantes do Curso de Licenciatura em História da UFMT, Campus Cuiabá. Revista do Departamento de História. Cáceres, UNEMAT Editora, v. 6, n. 1, 232p, 2015. Disponível em: <http://periodicos.unemat.br/index.php/historiae diversidade/article/view/870/859.> Acesso 16 de jun. de 2016.

SANTOS, H. A busca de um caminho para o Brasil: a trilha do circulo viciosos, São Paulo: Editora Senac, 2001.

SILVA, T. T. da. Documentos de identidade: uma introdução ás teorias do currículo. 3. ed. Belo Horizonte: Autentica, 2010.

SOUZA, N. S. Tornar-se negro, Rio de Janeiro: Graal, 1983.

SZESZ, C. M. et al. História do Brasil II. Ponta Grossa: UEPG/NUTEAD, 2011.
VEIGA. I. P. (org). Projeto Político Pedagógico da escola: uma construção possível. 20 ed. São Paulo: Papirus, 2005. 